\title{
Brote Epidémico de Listeriosis Neonatal
}

\author{
Dr. Hugo García U. ${ }^{1}$, Dra. M. Eugenia Pinto C. ${ }^{2}$, \\ Dr. Luis Ross R. ${ }^{3}$ y Dr. Gonzalo Saavedra E. 1 \\ Epidemic Outbreak of Neonatal Listeriosis
}

\begin{abstract}
We report an outbreak of five cases of Neonatal Listeriosis August 19 and Septcmber 4, 1980, at the Hospital San Juan de Dios's Nursery.

There was no clinical evidence to suspect Listeria infection in the mothers, except for one who had fever and positive isolation of Listeria monocy togenes from the endocervix.

Four neonates development septicemia, with meningeal involvement in three of them. The fifth casc developed a purulent meningitis.

According to the disease classification, 2 cases correspondcd to the early type, 2 cases to the intermediate and one case to the late form of the disease. lus.

One patient who had shock on admission died and one patient developed a secondary hidrocepha-

Two infants developed clinical and laboratory signs of DIC (Disseminated Intravascular Coagulation).

Treatment with Ampicillin-Gentamicin was clinically effective in four of them.

The epidemiological survey suggested the appearence of two primary cases which becane the reservoir of intrahospitalary spreading to the other neonates involved. The outbreak dissapeared after control meassures were instituted by a multiprofessional team.

The bacteriological techniques failed to isolate the bacteria from the Hospital enviroment and possible human reservoirs.
\end{abstract}

La Listeria Monocytógenes es un microorganismo conocido por su rol en infecciones del embarazo y del período neonatal.

En algunos paises especialmente en Europa, no solamente se denuncian casos esporádicos, sino zonas endémicas que presentan una incidencia relativamente alta de esta enfermedad ${ }^{1-2}$. En nuestro país las publicaciones sobre el tema son escasas y con referencja a casos esporádicos ${ }^{6}$, por lo cual creemos de inter és comunicar nuestra experiencia sobre un brote epidémico que aparece en Agosto y Septiembre de 1980 en la Unidad de Recién Nacidos del Hospital San Juan de Dios. Este brote de cinco casos" consecutivos signific 6 un desafío importante, ya que los aspectos epidemiológicos y patogénicos de esta enfermedad son controvertidos y discutibles.

\section{MATERIAL Y METODO}

Se describen los antecedentes obstétricos del parto, el cuadro clínico y la cronología de presentación de los cinco casos de Listeriosis Neonatal.

Caso 1. P.L., nace el 29/8/80 a las 22,14 hrs. producto de un embarazo de 40 semanas, sin antecedentes. mórbidos. Rotura artificial de membranas 5 horas antes del parto. Nacimiento apo-

1 Servicio de Pediatría Hospital San Juan de Dios.

2 Facultad de Medicina, División Ciencias Médicas Occidente. Unidad Bacteriológica. Universidad de Chile.

3 Epidemiología Servicio de Salud Occidente. yado por forceps, Apgar al minuto 5 y a los 5 minutos 8. Peso de nacimiento 2,900 grs. Se procedió a intubación y maniobras de resuscitación con buena respuesta clínica.

Su cuadro clínico se inició el mismo dia del nacimiento $(29 / 8 / 80)$, con fiebre, quejido, hipotonia y compromiso grave del estado general.

Caso 2. G.V., nace al mismo tiempo que el caso 1 , el $29 / 8 / 80$ a las 22,14 hrs. producto de un embarazo sin antecedentes mórbidos, con una edad gestacional de 39 semanas. Peso de nacimiento 2.350 grs. Parto eutócico, calificación Apgar al minuto de 7 y a los 5 minutos de 9 . El cuadro clínico se inicia al tercer dia de vida con fiebre, dificultad respiratoria y cianosis.

Caso 3. E.P., nace el $3 / 9 / 80$ a las $23,45 \mathrm{hrs}$. Producto de un embarazo de 37 semanas, con antecedentes maternos de sensación febril de dos dias antes del parto y rotura de membranas artificial durante el trabajo de parto.

Parto normal, con asfixia moderada que requirió ventilación con mascarilla y bolsa manual.

Los sintomas se inician el primer día de vida con crisis de apnea, fiebre, hipotonía, a los que so agregan convulsiones y petequias en la piel.

Caso 4. A.J., nace el 4/9/80 a las 09,15 hrs. Peso de nacimiento de 2.200 grs. Edad gestacional 36 semanas. Embarazo sin antecedentes mórbidos. Parto en posición podálica. Depresión respiratoria moderada por lo cual se ventila con mascarilla y bolsa manual. 
Los síntomas se inician al tercer día de vida con crisis de apnea e hipotonía. Al dia siguiente aparecen fenómenos hemorrágicos de la piel y luego signos de colapso cardiovascular.

Caso 5. 0.0., Nace el 4/9/80 a las 12 hrs. Peso de nacimiento de 3.050 grs. Embarązo de 39 semanas de gestación, sin antecedentes de importancia. Parto normal, rotura artificial de membranas durante el trabajo de parto. El puntaje de Apgar al nacimiento fue de 9 a los 1 y 5 minutos. Los sintomas de este R.N. comenzaron al noveno dia de vida, con fiebre, hipertonia y fontanela anterior tensa.

Los casos clínicos descritos se resumen en las Tablas 1 y 2 .

Tabla 1.

Antecedentes obstétricos y del parto en 5 casos Listeriosis Neonatal

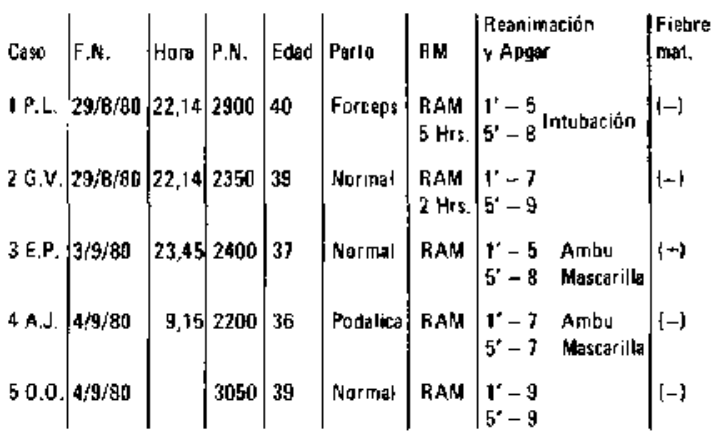

Tabla 2.

Características el ínicas iniciales sintomatología $y$ diagnóstico final en 5 casos de Listeriosis Neonatal

$\begin{array}{llll} & \text { Inicio } & \text { Signos } & \text { Compromiso } \\ \text { Caso } & \text { del cuadro } & \text { fundamentales } & \text { sistémico }\end{array}$

1 P.L. 1er. día Fiebre -

Hipotonıa.

Quejido

Septicemia

2 G.V. 3er. día Fiebre-Hipotonia

$\begin{array}{ll}\text { - Cianosis - } & \text { Septicemia }+ \\ \text { Trastornos } & \text { Meningitis } \\ \text { respiratorios } & \end{array}$

3 E.P. Ter. dia Fiebre - Apnea -

$\begin{array}{ll}\text { Hipotonia - } & \text { Septicemia }+ \\ \text { Convulsiones - } & \text { Meningitis + CIO } \\ \text { Petequias. } & \end{array}$

4 A.J. 3er. día Apnea-Hipotonia Septicemia + CID - Petequias - Shock (fallece)

50.0. go día Fiebre-Hipertonia Meningitis Fontanela tenso

El estudio de laboratorio de los 5 casos incluyó hemogramas, exámenes químicos y citológicos de liquido cefalorraquideo seriado y un exhaustivo estudio bacteriológico tanto de la madre como de? neonato.

En el recién nacido se tomaron hemocultivos ${ }^{3}$, cultivo de líquido cefalorraquídeo y eventualmente de secreción ocular, urocultivo y cultivo de secreción umbilical.

En las madres se tomaron muestras de secreción endocervical, que se sembraron en "Trypticase Soy Agar" (TSA) sangre e incubaron a $37^{\circ} \mathrm{C}$ con $5 \%$ de $\mathrm{CO}_{2}$; Una segunda fracción se depositô en $1 \mathrm{cc}$. de caldo peptonado y fue conservada a $4^{\circ} \mathrm{C}$ y subcul tivada 1 mes después.

Se tomaron medidas de pesquisa bacteriológica tratando de encontrar el germen, tanto en el medio ambiente, como con el personal en contacto con la embarazada en la Sala de Parto. Para cumplir estos objetivos se procedió a realizar cultivos bacteriológicos del ambiente, del material utilizado (sondas, instrumental, etc.) en las salas de pre-parto, parto $y$ atención inmediata $y$, además, de secreción fa. ringea y deposiciones del personal en contacto con por lo menos 3 de los recién nacidos infectados.

Desde el punto de vista bacteriológico se consideró a nuestros casos como brote epidémico, puesto que durante este período se produjo un aumento brusco en la incidenciz de una enfermedad, sin haber cambios en relación al tipo de muestra enviada al Laboratorio o a su procesamiento biológico.

Con los antecedentes clínicos y bacteriológicos se tomaron un conjunto de medidas epidemiológicas de control.

Se formó un Comité Coordinador para el análisis de los antecedentes y decisión sobre las medidas de control, luego se procedió al aislamiento de los casos infectados en la Sata de Recién Nacidos Infectados y se ordenó el cierre transitorio de la sala para Recién Nacidos inmediatos y habilitación de otro recinto con este fin. Al mismo tiempo se indicó el aseo y desinfección de las salas de parto, pre-parto, atención inmediata, además del uso estricto de delantal, mascarilla y guantes estériles para el manejo de cada recién nacido. El acceso del personal a la sala de parto y recién nacidos fue restringido al mínimo indispensabte.

\section{RESULTADOS}

El estudio bacteriológico permitió aislar del hemocultivo una Listeria Monocytógenes Serotipo 4 en los cuatro primeros casos (P.L., G.V., E.P., A.J.). En el quinto paciente el hemocultivo resultó infructuoso pero el cultivo de líquido cefalorraquídeo fue positivo para Listeria Monocytógenes Serotipo 4. El cultivo de líquido cefalorraquideo fue positivo además en los casos G.V. y E.P.

El cultivo de secreción ocular fue positivo en los casos E.P. y P.L.

Estos hallazgos bacteriológicos revelan la pre. sencia de cuatro casos de Septicemia, dos de ellas asociadas a foco meníngeo, una septicemia sin otra 
localización y una meningitis propiamente tal.

En la Tabla 3 se analizan los resultados bacteriológicos y del hemograma en los cinco casos de Listeria Neonatal.

\section{Tabla 3.}

Resultados de laboratorio en 5 casos de Listeriosis Neonatal

\begin{tabular}{|c|c|c|c|c|c|c|}
\hline \\
\hline Caso & $\begin{array}{l}\text { P. } \\
\text { Leuco. } \\
\text { citos }\end{array}$ & $\begin{array}{l}\text { Red. } \\
\text { Bac/Neuts. }\end{array}$ & $\begin{array}{l}\text { Hemocul- } \\
\text { tivo }\end{array}$ & LCR. & $\left|\begin{array}{l}\text { Cultivg } \\
\text { LCR }\end{array}\right|$ & $\mid \begin{array}{l}\text { Otros } \\
\text { Curltivos }\end{array}$ \\
\hline 1.P.L. & 10300 & 0.27 & $\begin{array}{l}\operatorname{LM}(H+H \\
\text { Serotipo } 4\end{array}$ & \begin{tabular}{|l} 
Prot. 0.4 \\
C 8
\end{tabular} & $1-1$ & $\begin{array}{l}\text { Secrecioin } \\
\text { acular it }\end{array}$ \\
\hline $2 G, V$, & 21500 & 0.2 & $\begin{array}{l}L M(+) \\
\text { Serotipo } 4\end{array}$ & \begin{tabular}{|l} 
Prot. 0.8 \\
L 414
\end{tabular} & $(+)$ & $(-)$ \\
\hline 3. E.P. & 9.900 & 0.23 & $\begin{array}{l}\text { L M }[+] \\
\text { Sarotipo } 4\end{array}$ & $\begin{array}{c}\text { Prot. } 0.2 \\
L 260\end{array}$ & $(+)$ & $\begin{array}{l}\text { Secreción nasal } \\
\text { y ocular }(+)\end{array}$ \\
\hline 4. A. & 8.600 & 0.3 & $\begin{array}{l}L M\{+\} \\
\text { Seratipo } 4\end{array}$ & $\begin{array}{c}\text { Prot. TH } \\
1670\end{array}$ & $(-)$ & $1-1$ \\
\hline 50.0. & 33100 & 0.04 & $1-1$ & $\mid \begin{array}{c}\mid \text { Prot. MfE } \\
\mid \text { L 1320 }\end{array}$ & $(+)$ & $\{-\}$ \\
\hline
\end{tabular}

LM $=$ Listcria monocy togenes

Prot. = Proteinas $\mathrm{g} . \mathrm{x}$ litro.

L. = Lcucocitos $\mathrm{x} \mathrm{mm}^{3}$

R. Leucocitos $=$ Recuento por $\mathrm{mm}^{3}$ de sangte periférica.

La evolución clínica de cuatro de nuestros casos se caracterizó por la buena respuesta a la asociación de Ampicilina y Gentamicina. La mejoria clinica se produce alrededor del quinto día de tratamiento. El caso AJ, que ingresa grave en shock, fallece al $5^{\circ}$ día de vida y el caso G.V. presenta una hidrocefalia residual al terminar el tratamiento.

La Tabla 4 resume la evolución clínica, tratamiento y complicaciones de los cinco casos.

Tabla 4.

Evolución clínica tratamien to y complicaciones en 5 casos de Listeriosis Neonatal

\begin{tabular}{|c|c|c|c|}
\hline Caso & Evolucián clinica & Tratamiento & Complicaciones \\
\hline I P.L. & $\begin{array}{l}\text { Mejoría clinica } \\
\text { al 3er. dia }\end{array}$ & $\begin{array}{l}\text { Ampicilina }+ \\
\text { Gentamicina (15 ds) }\end{array}$ & NO \\
\hline 2. G.V. & $\begin{array}{l}\text { Fiebre hasta } 10^{0} \\
\text { dias }\end{array}$ & $\begin{array}{l}\text { Ampicilina + } \\
\text { Gentamicina }(2 t \mathrm{ds})\end{array}$ & $\begin{array}{l}\text { Hidrocefalia } \\
\text { residual }\end{array}$ \\
\hline 3. E.P. & $\begin{array}{l}\text { Mejoria clínica } \\
5^{0} \mathrm{dia}\end{array}$ & $\begin{array}{l}\text { Ampıcilina }+ \\
\text { Gentamicina (15ds) }\end{array}$ & NO \\
\hline 4. A.J. & $\begin{array}{l}\text { Ingresa 3er. dia } \\
\text { fallece al } 5^{\circ} \text { día } \\
\text { Shock + CIO }\end{array}$ & $\begin{array}{l}\text { Dos días } \\
\text { Ampl. + Genta }\end{array}$ & Fallecte \\
\hline 5. 0.0 & $\begin{array}{l}\text { Mejoría desde } \\
5^{0} \text { día Hasp. }\end{array}$ & $\begin{array}{l}\text { Ampicilina }+ \\
\text { Gentamicina (15 ds) }\end{array}$ & NO \\
\hline
\end{tabular}

Nos pareció interesante la evolución que experimenta el cstudio citoquímico del líquido cefalorraquídeo en los tres pacientes en los cuales se detectó compromiso meningeo y estos resultados aparecen en la Tabla 5 .

La pesquisa bacteriológica resultó negativa tanto en el medjo ambiente externo como en el
Tabla 5.

Cabmios evolutivos del L CR en 5 casos de Listeriosis Neonatal

\begin{tabular}{|c|c|c|c|c|}
\hline Caso & 1er, dia & $3-5$ dias & 10 días & 14 dias \\
\hline 1. P.L. & $\begin{array}{l}\text { Prot. } 0.4 \\
\text { L }\end{array}$ & - & - & - \\
\hline 2. G.V. & $\begin{array}{l}\text { Prot. } 0.86-2.9 \\
\text { E } 414774\end{array}$ & - & $\begin{array}{l}\text { Prot. } 0.44 \\
\text { L 180 }\end{array}$ & $\begin{array}{l}\text { Prot } 0.18-0.11 \\
\text { L } 20 \cdot 12\end{array}$ \\
\hline 3 E.P. & $\begin{array}{l}\text { Prot. } 0.5-0.20 \\
L 2-260\end{array}$ & - & $\begin{array}{l}\text { Prot. } 0.16 \\
\text { L } 55\end{array}$ & $\begin{array}{l}\text { Prat. } 0.2 \\
\text { L } 3\end{array}$ \\
\hline 4. A.J. & $\begin{array}{l}\text { Prot. } 1 \mathrm{gr}-1.80 \\
\text { L } 300-670\end{array}$ & Fallece & & \\
\hline 5. 0.0 . & $\begin{array}{l}\text { Pro1. m/e } \\
\text { L } 1320\end{array}$ & $\begin{array}{l}\text { Prot. } 0.32 \\
\text { L } 51\end{array}$ & $\begin{array}{l}\text { Prot. } 0.22 \\
\text { L } 20\end{array}$ & - \\
\hline
\end{tabular}

personal. Solamente se ajsló Listeria Monocytógenes en el cultivo de secreción endocervical de la madre de E.P. (Caso 3) en la cual coincidió un cuadro febril de los últimos días del embarazo y un recién nacido con signos claros de infección en el momento del parto.

El aislamiento de Listeria Monocytógenes Serotipo 4 concuerda con el serotipo aisiado en los cinco recién nacidos infectados.

Como resultado del conjunto de medidas epidemiológicas no se detectaron nuevos casos, lo que demostró la eficacia y oportunidad de las normas señaladas.

\section{DISCUSION}

En la actualidad existe incertidumbre en relación a los aspectos epidemiológicos y patogénicos de la infección por Listeria Monocytógenes. Siempre se ha pensado que los animales y pájaros constituyen un reservorio importante del germen y que el hombre sólo es atacado esporádicamente. En la actualidad se da importancia al reservorio humano $y$ se menciona que 1 a $2 \%$ de los adultos son portadores del germen en su tubo digestivo (3.7).

El origen de la infección humana no es claro, la puerta de entrada discutible. (digestiva, respiratorio, conjuntival) y la manera como se disemina la enfermedad, especulativa.

La Listeria Monocytógenes ataca preferentemente a adultos o niños debilitados o inmuno suprimidos ${ }^{4}$, mujeres embarazadas y al neonato.

La razón por la cual la mujer embarazada es susceptible a esta enfermedad es desconocida. Habitualmente el cuadro clínico no reviste gravedad e incluso puede ser subclínico e inaparente. La mayoría de los casos se presenta como una enfermedad febril que evoluciona rápida y favorablemen$t \mathrm{c}^{5}$

Dependiendo de la gravedad del ataque bacteriano y la edad del embarazo en que se produce, el feto sufre con diferente intensidad, ya que la Listeriosis materna del primer trimestre del embarazo 
puede desencadenar un aborto; la Listeriosis del ulltimo trimestre del embarazo desencadena un parto prematuro con un producto altamente dañado o un mortinato: por iltimo, la madre portadora del germen en su canal genital, contamina al feto durante el parto, pudiendo ocasionar una Listeriosis neonatal de aparición intermedia o tardia.

A su vez, la Listeriosis neonatal presenta diferentes formas clínicas, que dependen del mecanismo por el cual el feto o recién nacido toman contacto con el germen: Si el feto recibe el germen como consecuencia de una infección aguda de la madre, ya sea a través de una infección transplacentaria o Corjoamniotitis aguda, la forma clínica predominante es la Septicemia precoz. Si el feto toma contacto con el germen en el momento del parto en un canal genital contaminado, la forma clínica más frecuente corresponde a la Septicemia de aparición intermedia (segundo o cuarto día). Si el recién nacido es manipulado o toma contacto con un medio ambiente externo contaminado con el germen, la traducción clínica puede ser una Septicemia de comienzo intermedio o una infección tardía semejante a la Meningitis purulents.

Si analizamos nuestros cinco pacientes observamos que dos de ellos, P.L. (Caso 1) y E.P. (Caso 3) corresponden a Septicemias de tipo precoz; este último (E.P.) aparece con una patogenia bastante clara, puesto que en él se asocian fiebre matema, cultivo endocervical positivo y signos de infección neonatal precoz. Los nin̄os G.V. (Caso 2), y A.J. (Caso 4) corresponden a infecciór neonatal por Listeria del tipo intermedio. Por último, el Caso 0.0., es típicamente tardío.

La mayoría de los autores concuerdan que la Listeriosis de los dos primeros dias de vida se debe a transmisión.materna y que los casos más tardíos corresponden a contaminación externa10-11-12.

Los casos de Septicemia y Meningitis o Septicemia y coagulación intravascular diseminada, corres. ponden a los de comienzo precoz e infectación masiva o comienzo intermedio, como ocurre en 4 de nuestros pacientes (P.L., E.P., G.V. y A.J.). También se señala su asociación exclusivamente con una Meningitis purulenta en casos tardios (Paciente 0.0.).

El conflicto aparece cuando se hace el análisis epidemiológico de los casos y no podemos evitar conclusiones especulativas.

E1 primer caso observado es P.L., que rápidamente presenta manifestaciones clínicas. Nace simultáneamente con el segundo caso G.V., quién inicia el cuadro clínico cuatro días después. Ambos partos fueron atendidos por la misma matrona. El tercer caso, E.P., nace $\mathbf{4}$ dias después que los anteriores, pero de una madre que ha presentado al final del embarazo un cuadro febril y en quién se comprueba Listeria Monocytógenes Serotipo 4 en secreción endocervjcal. El recién nacido nace comprometido y con manifestaciones clínicas precoces.

Horas después, el 4 de Septiembre de 1980, racen el cuarto y quinto caso (A.J., y O.O.), quienes no presentan signos de infección siendo dados de alta para reingresar después gravemente enfermos al quinto y noveno días, respectivamente. El primero de ellos es el único caso que fallece.

$A$ analizar el brote infeccioso se observa que no existe coincidencia geográfica en la ubicación de los edsos en el Servicio de Recién Nacidos, salvo su paso por las salas de preparto, parto y atención inmediata, perteneciendo a estos recintos el único personal comút a todos o parte de los casos.

De acuerdo a estos elementos se plantean varias alternativas en relación a la fuente de infección:

-. Aparición de dos fenómenos de infección cruzada, en los cuales el caso 1 (G.V.) y el caso 3 (E.P.) fueron primarios, diseminando por vía indirecta a los casos contiguos.

- Existencia de personal en la sala de parto o atención inmediata portadora del germen.

Existencia de un reservorio ambiental cn la sala de proparto, parto o atención inmediata, que haya implicado contaminación de los recién nacidos.

Nos parece que la primera alternativa es la más coherente $e$ implica aceptar que se han presentado dos casos de Listeriosis primaria independientes entre sí, pero en un lapso de tiempo corto (4 dias) $y$, que cada uno de ellos de alguna manera contaminó el medio ambiente externo de la sala de parto, preparco o de la sala de atención inmediata, siendo el instrumental o las personas vectores del germen a los reciét nacidos contactos.

Ambos casos primarios nacen con una Septicemia precoz lo que avalaría que el recién nacido tomó contacto can el germen antes del parto. Los otros casos son de aparición intermedia o tardía lo que explica que sean producto de una contaminación de1 medio ambiente. La segunda opción no nos parece muy probable puesto que no se demostró Listeria Monocytógenes en el personal que tomó contacto con los recién nacidos infectados. Además, no aparecen nuevos casos a pesar de que no medió acción terapéutica sobre el personal, que continuó actuando en la sala de preparto, parto y atención inmediata.

La tercera posibilidad aparece parcialmente probable puesto que de alguna manera y en forma transitoria hubo una contaminación del medio externo de la sala de parto o de la sala de atención inmediata.

Tres de nuestros casos nacieron con asfixia. El Caso 1 (P.L.) necesitó maniobras de resucitación 


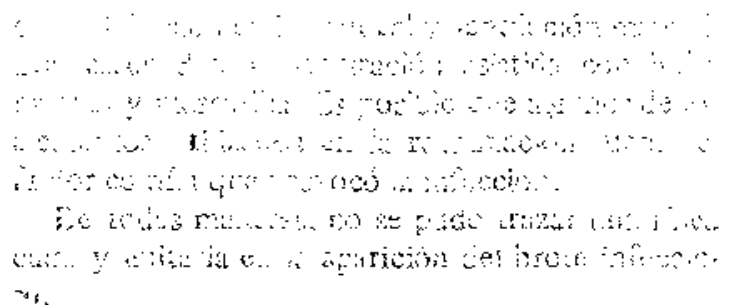

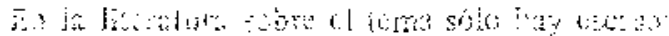

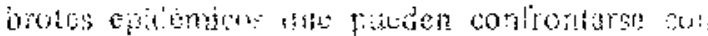

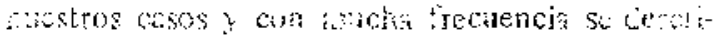

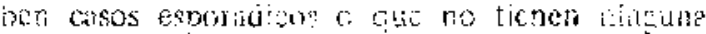

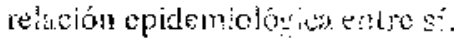

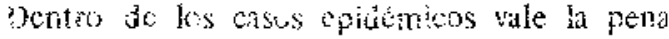

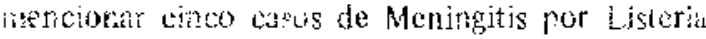
Monocytógenes el! rectria maciłos qulte se preseataror en el Certro die Conurol de Enfermedades aliccciosas en Atlanta, Georgia. (1975). En estos

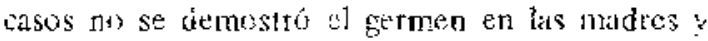
como clibicamente eran casos de apdricion turdía se hizo un exhaustivo estudio del medio ambienti $y$ personal sin logret demostrat la Listeria Monocylogenes ${ }^{11}$

Tombisin es istevesante mencionar dos brotes evidénicos aue 30 iresentaron on el Hospitial Gincrai die Matmoe de Suecia $(1977)$ y que se ascriojall a lo uoservado en imestro Servicio. El al primero de allos ci recien nacido nace gravemento enfermo y contammil a un scogundo recién reacido atue nuce breves momentos desplés y hace un: Meningitis tardia. Sil segundo brote tiene las risismas caracter isticas de un recićn nacido gue nnce muy gr?vemente enfermo y que concamina a otros dos reciér nacidos. los que presentan posterormente enterocolitis necrotizante.

El análisis epidemiológico de estos brotes reveló que los dos casos que nacen gravemente alcetados por 1a enfermedad fueron los casos primarios y los casos siguientes correspondieron clínicamente a las formas tardías por contaminación externa. E] estudio ulterior demostró que un mismo termómetro había sido usado para varios recién nacidos ${ }^{12}$.

Desde el punto de vista bacteriológico en nuestros casos se apreció un buen rendimiento para aislar el germen en las infecciones aguda (LCR. sangre, secreciones conjuntivales) y un bajo rendimiento en la pesquisa del ambiente y de los reservorios humanos, experiencia que coincide ampliamente con lo descrito por la literatura del te$\mathrm{ma}^{11-13}$.

El rendimiento bacteriológico presumiblemente aumenta cuando se conserva la tórula en $1 \mathrm{cc}$. de agua destilada o bien, cuando se agita la tórula en solución buffer fosfato con centrifugación posterior y resuspensión en $4,5 \mathrm{cc}$. de "Trypticase Soy Broth", manteniéndola por 1 a 5 meses con subcultjwos posteriores en Trypticase Soy Agar (TSA)

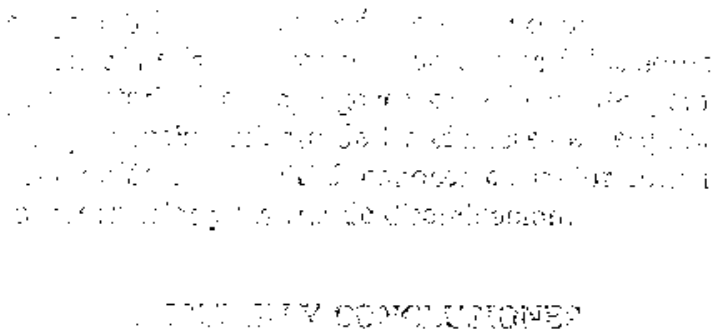

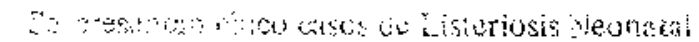

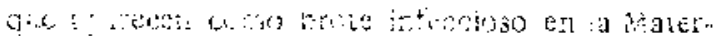

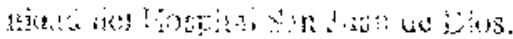

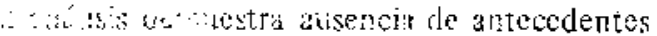

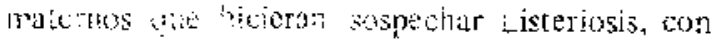

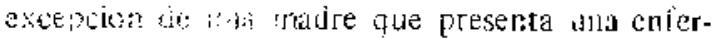

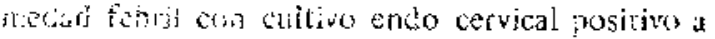
Listria Horlocitorones.

is: la clasificacion de formas clínicas dos casus currespondes a la borou trecoz de la enfermedad. dis casos it a foma intermedia y uno a la foma Fitidi.

Los cuadros dínicos corresponden en cuatro aciclies, a Sevlicemids existiendo localizaciones montrogs tre tres cie ellos. El quinto caso corresondió a ta Meningitis purulenta.

Pos a asos presenturon signos clínicos $y$ de Laboratoro de romiziación intravascular discminada.

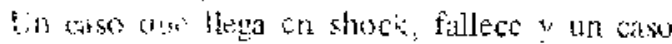
g̨uecir un una siij:ocetalea sccundaria.

Fristió buería respuesta al tratamicrito con la usuciacion Ampicilina más Gentamicina en el resto se los pacientes.

Ei análisis cpidemiológico sugiere la presencia de dos casos grimarios de Listeriosis que a través de la contaminación del medio ambiente comprometiernn a los otros recién nacidos.

Las medidas de control tomadas por el equipo multiprofesional fueron efectivas. puesto que después del 4 de Septiembre de 1980 no aparecen nuevos casos.

Las técnicas de pesquisa bacteriológica son de bajo rendiniento para demostrar la presencia del germen en el ambiente y los reservorios humanos.

\section{AGKADECIMIENTOS}

Agradecemos a los Dres. M. Hopor y A.B. Silva del Institu to de Salud Pública de Chile, por su colaboracjón en la Serotipifícación de las cepas de Listeria Monocytógenes.

\section{REFERENCIAS}

I.P. Relier, C. Amiel-Tison, J.K. Ravel. Listeriose Nconatale. J. Gynecol. Obstet. Biol. Reprod. 6: 367 , 1977.

2 S. Larsson, S. Cronberg, S. Windblad. Listeriosis during pregnancy and neonatal period in Sweden 1958-1974. Acta Patditar.-Scand. 68: 485, 1979. 
${ }^{3} S$. Larsson. Epidemiology of Listeriosis en Sweden 1958-1974. Scand. I. Infect. Dis. 11:47, 1979.

A Green H., C. Macaulay M. Hospital Outbreak of Listeria Monocytogenes Scpticacmia. Lancet 11: $1039,1978$.

5 Hood, $M$. Listeriosis a an infection of Pregnancy manifested in the New Born. Pediatrics 27: 390. $196 \mathrm{~L}$.

5 Pino M., Schuster A. Listeriosis humana con especial referencia a recién nacido. Ref. Chil. Pediatr. 36: 614, 1967.

7 D.M.O. Becroft, K. Farmer, R.J. Seddon, Epidenic Listeriosis in the Nowborn. Br. Med. J. 3: 747, 1971.

- Ienelthe E.H. Manual of Clinical Mictobiology. An. Soc, Microbiology Washington D.C. 3or. Ed. Pag. 139, 1980.
${ }^{7}$ Ray G. and Wedgwood R. Neonatal Listeriosis. Pcdiatrics $34: 378,1964$.

10 Filice $G$. , Fuman $H$. Listeria Monocytogencs Infection in Neonates. Investigation of an epidemies. J. Infect. Dis. 138: 78, 1978 .

1 I L Larson. Listeria monncytogenes causing hospital acquired cutecocolitis and meningitis in sewbon infants. Department of infections diseases, General Hospitill. Br. Med. J, 12:473, 1978.

12 W.L. Albritom W.L. Wiggins Feeley J.C. Distribution of Serotypes in relation to age at onset of disease. J. Pediatr. 88: 481, 1976. 